\title{
Variação sazonal da concentração de nutrientes em folhas de bananeiras, no Vale do Ribeira-SP
}

\section{Seasonal variation of nutrients leaves concentration of banana plants in Vale do Ribeira-SP}

\author{
Leandro José Grava de Godoy ${ }^{1 *}$; Stéfano Gongora Goçalo; \\ José Carlos de Mendonça ${ }^{3}$; Adão Bernardo ${ }^{4}$
}

\section{Resumo}

O Vale do Ribeira, SP, tem como principal atividade agropecuária o cultivo da bananeira, sendo responsável pela maior parte da produção dessa frutífera no estado de São Paulo. O equilíbrio nutricional da planta é um dos fatores mais importantes para que esta consiga completar o ciclo e alcançar alta produtividade. Com o objetivo de avaliar a variação sazonal da concentração foliar de nutrientes em bananeiras cultivadas no Vale do Ribeira-SP, foram utilizados 252 resultados de análise química de nutrientes do tecido vegetal, coletados no período de agosto de 2009 a setembro de 2010, de 18 propriedades representativas na região, dez cultivadas com bananeira do subgrupo Cavendish e oito do subgrupo Prata. A maior variação entre os macronutrientes ocorreu para o K e o S e entre os micronutrientes, principalmente, para o Fe e o B. Em algumas datas da avaliação, houve maior concentração foliar de P, K, Ca e Zn, nas bananeiras do subgrupo Cavendish, enquanto as bananeiras do subgrupo Prata apresentaram maior concentração foliar, principalmente, de Mn, B e N. As condições climáticas, principalmente a chuva, influenciaram as concentrações foliares de nutrientes, com destaque para o K, N, S, B e Fe.

Palavras-chave: Adubação, estado nutricional, banana, Musa sp

\begin{abstract}
The Vale do Ribeira, SP, main agricultural activity is the banana crop, which accounts for most of this fruit production in the State of São Paulo. The nutritional balance of the plant is one of the most important factors for the banana plant can complete the cycle and achieve high productivity. Aiming to evaluate the seasonal variation of leaf nutrient concentration in banana plants in Vale do Ribeira-SP, we used the results of 252 chemical analyses of plant tissue, collected from August 2009 to September 2010, in the 18 representative properties for the region, ten cultivated with subgroup Cavendish banana plant and eight of subgroup Prata banana plant. The largest variation between the macronutrient occurred for $\mathrm{K}$ and $\mathrm{S}$, and among the micronutrients, especially for $\mathrm{Fe}$ and $\mathrm{B}$. In some dates of evaluation, there was a higher leaf concentration of $\mathrm{P}, \mathrm{K}, \mathrm{Ca}$ and $\mathrm{Zn}$, in subgroup Cavendish banana plants, while the subgroup Prata banana plants showed higher leaf concentration, especially of Mn, B and N. Climatic conditions, especially rain, influenced the leaf nutrient content, especially for K, N, S, B and Fe.
\end{abstract}

Key words: Fertilization, nutritional status, banana, Musa sp

\footnotetext{
${ }^{1}$ Prof. Dr. Assistente do Campus Experimental de Registro, Universidade Estadual Paulista, UNESP, Registro, SP. E-mail: legodoy@registro.unesp.br

${ }^{2}$ Discente do curso de Agronomia do Campus Experimental de Registro, UNESP. E-mail: stefano.gocalo@agronomo.eng.br

${ }^{3}$ Eng $^{\mathrm{o}} \mathrm{Agr}^{\mathrm{o}}$, Comtécnica Comércio e Representação de Produtos Agropecuários. Registro, SP. E-mail: mendoncajc@uol.com.br

${ }^{4}$ Discente do curso de Ciências Biológicas das Faculdades Integradas do Vale do Ribeira, UNISEPE, Registro, SP. E-mail: adão. bernardo10@yahoo.com.br

*Autor para correspondência
} 


\section{Introdução}

A banana (Musa spp.) é uma das frutas mais consumidas no mundo na forma in natura, cultivada em muitos países tropicais, o Brasil é responsável por $8 \%$ da produção total mundial que chegou a 90 milhões de toneladas em 2009 (FAO, 2010). Esta cultura pode ser encontrada no país inteiro, sendo os estados maiores produtores: Bahia, São Paulo, Santa Catarina, Pará e Minas Gerais (BORGES; SOUZA, 2009).

A região do Vale do Ribeira tem como principal atividade agropecuária o cultivo da bananeira, com área cultivada de aproximadamente 34,8 mil ha, sendo responsável pela maior parte da produção dessa frutífera no estado de São Paulo (IEA, 2010).

O equilíbrio nutricional da planta é um dos fatores mais importantes para que esta consiga completar o ciclo e alcançar alta produtividade econômica (SILVA; CARVALHO, 2005). A análise química foliar é um método muito eficaz para detectar desequilíbrios e auxiliar na recomendação de adubação em bananeiras (TEIXEIRA; ZAMBROSI; NETO, 2007), diminuindo desperdícios pelo uso incorreto de fertilizantes. Além disso, a diagnose foliar pode ser usada como método de avaliação de fertilidade do solo pela correlação existente entre a concentração dos nutrientes nas plantas e a disponibilidade na solução do solo (HARGER; FIORETTO; RALISCH, 2003). A variação da concentração dos nutrientes depende de vários fatores como cultivar; estádio fenológico; clima; características físico-químicas do solo; tratos culturais; tipo, época e forma de adubação; e competição entre os nutrientes (TURNER; LAHAV, 1985; MALAVOLTA; VITTI; OLIVEIRA, 1997; BUSQUET, 2006). Nos bananais podem-se encontrar plantas em diversos estádios de desenvolvimento, assim os bananais apresentam plantas em florescimento durante $\mathrm{o}$ ano todo, período no qual a planta necessita do suprimento de nutrientes. O período tradicional de adubação da cultura da banana na região é de agosto a abril, onde ocorrem alterações na temperatura e principalmente na quantidade de chuva, o que pode afetar a eficiência de utilização dos fertilizantes.

Assim, o estudo da variação sazonal do estado nutricional, em bananais do Vale do Ribeira-SP, pode fornecer subsídios sobre a eficiência do manejo nutricional utilizado pelos produtores, sobre a influência das condições climáticas na nutrição da bananeira e auxiliar nos ajustes nas recomendações de adubação.

Objetivou-se com este trabalho avaliar a variação sazonal da concentração foliar de nutrientes em bananeiras cultivadas no Vale do Ribeira-SP, para verificar o efeito do clima e manejo da cultura no estado nutricional da bananeira.

\section{Material e Métodos}

Foram utilizados 252 resultados de análise química de nutrientes do tecido vegetal, coletados no período de agosto de 2009 a setembro de 2010, de 18 propriedades representativas no Vale do RibeiraSP, dez cultivadas com bananeira do subgrupo Cavendish e oito do subgrupo Prata, apresentadas respectivamente, nos municípios de Pariquera-Açu $(1 ; 1)$, Cajati $(0 ; 6)$, Eldorado $(0 ; 1)$, Jacupiranga $(4 ; 0)$, Sete Barras $(2 ; 0)$ e Registro $(3 ; 0)$.

As propriedades foram caracterizadas com a ordem e subordem do solo por meio do mapa do levantamento Pedológico de Reconhecimento - Semidetalhado da Região do Rio Ribeira de Iguape no Estado de São Paulo (SAKAI; LEPSCH; AMARAL, 1983), mapa do levantamento de reconhecimento com detalhes dos solos da região do rio Ribeira de Iguape, SP (LEPSCH et al., 1999) e meio do mapa pedológico das sub-bacias hidrográficas dos rios Jacupiranga e Pariquera-Açu, SP (LOURES, 2008); resultados de análise química do solo para fins de fertilidade, nas camadas de 0 a 20 e 20 a $40 \mathrm{~cm}$ de profundidade, situação (topografia) do bananal e o cultivar utilizado (Tabelas 1 e 2). 
Tabela 1. Características das propriedades com bananais, dos quais foram coletadas as amostras foliares no período de julho de 2009 a setembro a 2010. (Vale do Ribeira, SP).

\begin{tabular}{llllll}
\hline Pr. & Município & Subgrupo & Cultivar & Situação & Ordem do solo \\
\hline 1 & Sete Barras, SP & Cavendish & Nanicão & plano & Gleissolo Háplico \\
2 & Sete Barras, SP & Cavendish & Nanicão & plano & Gleissolo Háplico \\
3 & Cajati,SP & Prata & Prata-Anã & morro & Latossolo Vermelho Amarelo \\
4 & Cajati,SP & Prata & Prata-Anã & morro & Latossolo Vermelho Amarelo \\
5 & Cajati,SP & Prata & Prata-Anã & morro & Argissolo Vermelho Amarelo \\
6 & Cajati,SP & Prata & Prata-Anã & morro & Argissolo Vermelho Amarelo \\
7 & Cajati,SP & Prata & Prata-Anã & morro & Argissolo Vermelho Amarelo \\
8 & Cajati,SP & Prata & Prata-Anã & morro & Argissolo Vermelho Amarelo \\
9 & Pariquera-Açu, SP & Prata & Prata-Anã & plano & Latossolo Amarelo \\
10 & Pariquera-Açu, SP & Cavendish & Nanicão & plano & Latossolo Amarelo \\
11 & Jacupiranga, SP & Cavendish & Nanicão & baixada & Cambissolo Háplico \\
12 & Jacupiranga, SP & Cavendish & Nanicão & baixada & Cambissolo Háplico \\
13 & Jacupiranga, SP & Cavendish & Nanicão & baixada & Cambissolo Háplico \\
14 & Jacupiranga, SP & Cavendish & Nanicão & baixada & Cambissolo Háplico \\
15 & Eldorado, SP & Prata & Prata-Anã & morro & Argissolo Vermelho Amarelo \\
16 & Registro, SP & Cavendish & Nanicão & plano & Gleissolo Háplico \\
17 & Registro, SP & Cavendish & Nanicão & plano & Gleissolo Háplico \\
18 & Registro, SP & Cavendish & Grande Naine & plano & Gleissolo Háplico \\
\hline
\end{tabular}

Fonte: Elaboração dos autores.

Para as análises foliares coletaram-se amostras compostas de 10 plantas aleatoriamente em cada propriedade, uma vez ao mês, em talhões selecionados. Coletou-se da terceira folha a partir do ápice, de 10 a $15 \mathrm{~cm}$ da região central do limbo (sem a nervura central), de plantas no início do florescimento (com a inflorescência no estádio em que todas as pencas femininas encontram-se descobertas, sem brácteas, e com, no máximo, três pencas de flores masculinas) como recomendado por Quaggio, Raij e Piza Júnior (1997).

Nas amostras foram determinadas as concentrações de macro, micronutrientes e sódio (Na) de acordo com Malavolta, Vitti e Oliveira (1997). Os resultados foram plotados com as médias das concentrações em função da data, para bananeira Prata e Nanica e foram adicionados os valores adequados (limite da deficiência e do excesso) para o cultivo de bananeira (QUAGGIO; RAIJ; PIZA JÚNIOR, 1997).

A variação das concentrações de cada nutriente no período foi calculada pelo coeficiente de variação obtendo-se os resultados em porcentagem.

Para interpretação dos resultados, devido a de falta de valores de referência para o subgrupo Prata no estado de São Paulo, foram considerados os mesmos para o subgrupo Cavendish e Prata.

Os resultados das análises de macro, micronutrientes e sódio foram submetidos ao teste estatístico T (Bonferroni) a 5\%, conforme Furtado et al. (2009), visando verificar a diferença da concentração dos nutrientes e do sódio do subgrupo Prata em relação ao Cavendish. 
Tabela 2. Características químicas para fins de fertilidade, de amostras de solo, coleadas nas camadas de 0 a 20 e 20 a $40 \mathrm{~cm}$ de profundidade, das propriedades com bananais, dos quais foram coletadas as amostras foliares no período de julho de 2009 a setembro a 2010. (Vale do Ribeira, SP).

\begin{tabular}{|c|c|c|c|c|c|c|c|c|c|c|c|c|c|c|c|c|}
\hline \multirow{2}{*}{ Pr. } & \multirow{2}{*}{ Prof. ${ }^{1}$} & $\mathrm{pH}^{2}$ & $\mathrm{Al}^{3}$ & $\mathrm{Ca}$ & $\mathrm{Mg}$ & $\mathrm{K}$ & CTC & $\mathrm{V}$ & MO & $\mathrm{P}$ & $\mathrm{S}$ & $\mathrm{B}$ & $\mathrm{Fe}$ & $\mathrm{Mn}$ & $\mathrm{Cu}$ & $\mathrm{Zn}$ \\
\hline & & & \multicolumn{5}{|c|}{------ $\mathrm{cmol}_{\mathrm{c}} \mathrm{dm}^{-3}$} & $\%$ & $\mathrm{~g} \mathrm{dm}^{-3}$ & \multicolumn{7}{|c|}{ - } \\
\hline \multirow{2}{*}{1} & 1 & 5,4 & 0,0 & 6,1 & 2,8 & 0,3 & 11,6 & 79 & 20 & 106 & 9 & 0,6 & 60 & 20 & 3,3 & 10 \\
\hline & 2 & - & - & - & - & - & - & - & - & - & - & - & - & - & - & - \\
\hline \multirow{2}{*}{2} & 1 & 4,8 & 0,0 & 6,0 & 1,9 & 0,3 & 12,2 & 67 & 22 & 155 & 4 & 0,2 & 216 & 20 & 4,0 & 27 \\
\hline & 2 & 4,0 & 1,0 & 3,9 & 1,3 & 0,2 & 13,8 & 39 & 14 & 39 & 22 & 0,3 & 348 & 12 & 3,5 & 10 \\
\hline \multirow{2}{*}{3} & 1 & 5,3 & 0,0 & 6,9 & 1,2 & 0,4 & 11,2 & 76 & 29 & 127 & 58 & 0,3 & 36 & 62 & 1,4 & 17 \\
\hline & 2 & 4,9 & 0,2 & 3,8 & 0,8 & 0,2 & 9,0 & 54 & 20 & 29 & 87 & 0,2 & 50 & 27 & 1,7 & 6 \\
\hline \multirow{2}{*}{4} & 1 & 5,2 & 0,0 & 5,2 & 1,2 & 0,2 & 9,0 & 71 & 28 & 66 & 10 & 0,3 & 125 & 53 & 1,6 & 11 \\
\hline & 2 & 4,7 & 0,2 & 2,8 & 0,9 & 0,1 & 7,0 & 53 & 17 & 26 & 15 & 0,3 & 207 & 26 & 1,6 & 3 \\
\hline \multirow{2}{*}{5} & 1 & 5,5 & 0,0 & 5,1 & 1,3 & 0,2 & 8,4 & 77 & 29 & 14 & 52 & 0,3 & 104 & 44 & 2,4 & 11 \\
\hline & 2 & 5,0 & 0,2 & 4,0 & 1,1 & 0,2 & 8,7 & 58 & 20 & 5 & 48 & 0,4 & 154 & 32 & 2,5 & 11 \\
\hline \multirow{2}{*}{6} & 1 & 4,9 & 0,0 & 4,2 & 0,8 & 0,3 & 8,4 & 62 & 28 & 90 & 20 & 0,3 & 46 & 24 & 3,3 & 8 \\
\hline & 2 & 4,4 & 0,5 & 1,8 & 0,6 & 0,1 & 6,4 & 39 & 16 & 19 & 69 & 0,3 & 56 & 6 & 1,7 & 3 \\
\hline \multirow{2}{*}{7} & 1 & 5,3 & 0,0 & 5,8 & 1,4 & 0,2 & 9,8 & 74 & 29 & 88 & 22 & 0,2 & 81 & 42 & 4,8 & 69 \\
\hline & 2 & 4,3 & 0,5 & 1,9 & 0,8 & 0,2 & 8,4 & 34 & 18 & 19 & 79 & 0,2 & 111 & 12 & 3,7 & 13 \\
\hline \multirow{2}{*}{8} & 1 & 5,6 & 0,0 & 7,2 & 1,8 & 0,4 & 11,4 & 83 & 31 & 76 & 8 & 0,3 & 29 & 76 & 9,5 & 28 \\
\hline & 2 & 4,8 & 0,0 & 3,4 & 1,0 & 0,2 & 7,9 & 58 & 21 & 24 & 46 & 0,2 & 72 & 26 & 9,9 & 8 \\
\hline \multirow{2}{*}{9} & 1 & 5,2 & 0,0 & 4,6 & 1,0 & 0,1 & 8,2 & 69 & 28 & 70 & 9 & 0,3 & 565 & 2,0 & 1,0 & 7 \\
\hline & 2 & 4,6 & 0,3 & 1,7 & 0,5 & 0,1 & 6,3 & 36 & 17 & 49 & 10 & 0,3 & 760 & 1,5 & 0,5 & 4 \\
\hline \multirow{2}{*}{10} & 1 & 5,1 & 0,0 & 9,0 & 1,4 & 0,4 & 12,5 & 86 & 28 & 165 & 17 & 0,3 & 240 & 5,0 & 2,0 & 26 \\
\hline & 2 & 4,8 & 0,0 & 2,7 & 0,9 & 0,3 & 7,2 & 54 & 17 & 17 & 15 & 0,3 & 790 & 0,5 & 0,5 & 7 \\
\hline \multirow{2}{*}{11} & 1 & 4,2 & 0,7 & 1,7 & 0,8 & 0,3 & 9,6 & 2 & 28 & 75 & 2,4 & 0,3 & 372 & 6,5 & 1,2 & 27 \\
\hline & 2 & - & - & - & - & - & - & - & - & - & - & - & - & - & - & - \\
\hline \multirow{2}{*}{12} & 1 & 4,2 & 0,7 & 3,6 & 1,4 & 0,1 & 12,3 & 42 & 36 & 23 & 36 & 0,3 & 500 & 3,5 & 0,7 & 3 \\
\hline & 2 & 3,8 & 1,5 & 0,8 & 0,5 & 0,1 & 12,3 & 11 & 24 & 16 & 42 & 0,3 & 690 & 1,5 & 0,7 & 2 \\
\hline \multirow{2}{*}{13} & 1 & 4,4 & 0,5 & 2,1 & 0,8 & 0,3 & 8,2 & 39 & 29 & 75 & 23 & 0,2 & 460 & 20 & 2,5 & 6 \\
\hline & 2 & 4,0 & 0,9 & 1,3 & 0,6 & 0,2 & 7,6 & 27 & 17 & 16 & 32 & 0,3 & 670 & 14 & 2,0 & 3 \\
\hline \multirow{2}{*}{14} & 1 & 5,5 & 0,0 & 4,3 & 1,0 & 0,2 & 7,2 & 76 & 21 & 69 & 8 & 0,2 & 246 & 10 & 1,5 & 3 \\
\hline & 2 & - & - & - & - & - & - & - & - & - & - & - & - & - & - & - \\
\hline \multirow{2}{*}{15} & 1 & 4,6 & 0,3 & 3,0 & 0,9 & 0,4 & 9,0 & 48 & 43 & 125 & 40 & 0,3 & 395 & 3,5 & 0,7 & 15 \\
\hline & 2 & 4,2 & 1,0 & 0,6 & 0,3 & 0,2 & 7,2 & 15 & 28 & 27 & 47 & 0,3 & 430 & 0,5 & 0,3 & 15 \\
\hline \multirow{2}{*}{16} & 1 & 5,8 & 0,0 & 7,0 & 3,2 & 0,2 & 12,1 & 85 & 25 & 79 & 10 & 0,3 & 390 & 29 & 7,2 & 38 \\
\hline & 2 & 5,8 & 0,0 & 5,3 & 2,5 & 0,1 & 9,6 & 82 & 15 & 48 & 7 & 0,3 & 550 & 9 & 7,0 & 12 \\
\hline \multirow{2}{*}{17} & 1 & 5,0 & 0,0 & 5,2 & 2,3 & 0,6 & 11,4 & 71 & 38 & 165 & 42 & 0,2 & 250 & 7 & 5,0 & 8 \\
\hline & 2 & 4,1 & 1,0 & 2,8 & 1,6 & 0,3 & 10,8 & 44 & 29 & 155 & 22 & 0,3 & 243 & 2 & 6,0 & 5 \\
\hline \multirow{2}{*}{18} & 1 & 5,7 & 0,0 & 7,4 & 2,8 & 1,5 & 13,4 & 87 & 24 & 125 & 11 & 0,4 & 178 & 18 & 2,0 & 26 \\
\hline & 2 & 5,0 & 0,0 & 3,9 & 2,0 & 0,5 & 9,3 & 69 & 14 & 29 & 16 & 0,2 & 258 & 9 & 2,0 & 6 \\
\hline
\end{tabular}

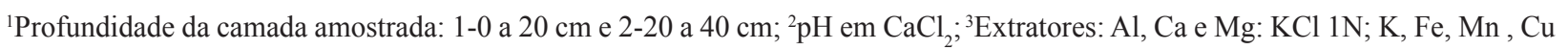
e Zn: Mehlich-1; P: resina; B: água quente; S: fosfato monocálcico.

Fonte: Elaboração dos autores. 
Os dados de precipitação e temperatura (julho/2009 a maio/2010) foram obtidos a partir do Centro Integrado de Informações Agrometeorológicas (CIIAGRO, 2010) para auxiliar na discussão dos resultados em relação à variação sazonal.

\section{Resultados e Discussão}

A variação na concentração dos nutrientes e do sódio, de agosto de 2009 a setembro de 2010, para bananeira do subgrupo Cavendish e Prata, respectivamente, foi a seguinte, para: $\mathrm{N}(6,9$ e $7,3 \%)$; $(7,8$ e $6,9 \%)$; K (25,1 e 30,7\%); Ca $(11,3$ e $4,0 \%) ; \operatorname{Mg}(9,3$ e $6,0 \%) ; \mathrm{S}(17,0$ e $17,5 \%) ; \mathrm{Zn}$ $(15,4$ e $20,9 \%) ; \mathrm{Cu}(14,4$ e $22,5 \%) ; \mathrm{Mn}(20,1$ e $11,9 \%)$; Fe $(27,0$ e $44,0 \%)$; B (23,3 e $25,3 \%)$ e $\mathrm{Na}(33,0$ e $37,0 \%)$. A maior variação entre os macronutrientes ocorreu para o $\mathrm{K}$ e o $\mathrm{S}$ e entre os micronutrientes, principalmente, para o Fe e o B. $\mathrm{O} \mathrm{K}, \mathrm{S}$ e B são suscetíveis à lixiviação (WERLE; GARCIA; ROSOLEM, 2008; ROSOLEM; BÍSCARO, 2007; FOLONI; ROSOLEM, 2006) o que pode favorecer a variação na disponibilidade no solo, e conseqüentemente, na concentração na planta. No caso do potássio, o parcelamento da adubação durante o período de adubação, também pode ter contribuído para esta maior variação. Para o Fe a disponibilidade pode variar muito com as condições de oxiredução do solo. Segundo Abreu, Fernandes e Ruivo (2007) o Fe foi o nutriente que apresentou maior variação nos seus teores com a inundação, cujo aumento foi superior a 1.000 \% no período de maior inundação do solo. Para o norte de Minas Gerais, Silva e Rodrigues (2001) observaram maior variação da concentração foliar, em bananeira do subgrupo Prata, para o Ca dentre os macronutrientes, devido o uso de água de irrigação de poço com alta concentração de $\mathrm{Ca}$, e de $\mathrm{Cu}$ e $\mathrm{Mn}$, dentre os micronutrientes, devido à aplicação de calda cúprica, manejo da irrigação e tipo de solo.

As baixas temperaturas e a alta quantidade de chuva ocorridas em julho de 2009 (Figura 1A e 2B) podem ter reduzido a absorção de N (TURNER; LAHAV, 1985) o que pode explicar as concentrações foliares de $\mathrm{N}$ ficarem abaixo do adequado para a cultura, nesta data (Figura 2A). Em janeiro de 2010, também houve redução da concentração de $\mathrm{N}$ na folha, neste caso, devido somente ao excesso de chuva (Figura 1A) o que pode ter favorecido a lixiviação do N (MUNOZ-CARPENA et al., 2002). Houve elevação gradual de agosto a novembro de 2009 e de fevereiro a maio de 2010, que coincidiu com as épocas de adubação realizada tradicionalmente pelos produtores da região, e pela oportunidade devido à diminuição da ocorrência de chuva nestes meses (Figura 1A). O aumento da temperatura e o maior crescimento das plantas, também podem favorecer a absorção do nutriente, contribuindo para a elevação da concentração foliar (TURNER; LAHAV, 1985). Leonel e Tecchio (2009) também observaram aumento da concentração de $\mathrm{N}$ em folhas de figueira, a partir de setembro, devido fatores mais propícios ao crescimento das plantas (condições de temperaturas e hídricas mais favoráveis). Considerando a concentração adequada de N, na folha de bananeira cv. Prata-Anã, para o norte de Minas Gerais (25 a $29 \mathrm{~g} \mathrm{~kg}^{-1}$ ), sugerida por Silva et al. (2002) somente em agosto de 2009, fevereiro e março de 2010, as plantas deste cultivar estariam deficientes em N (Figura 2A). 
Figura 1. A. Média da precipitação entre os municípios $(\mathrm{mm})$; B. Temperatura máxima, média e mínima, dos municípios de Registro, Pariquera-Açu, Jacupiranga e Sete Barras-julho/2009 - setembro/2010.

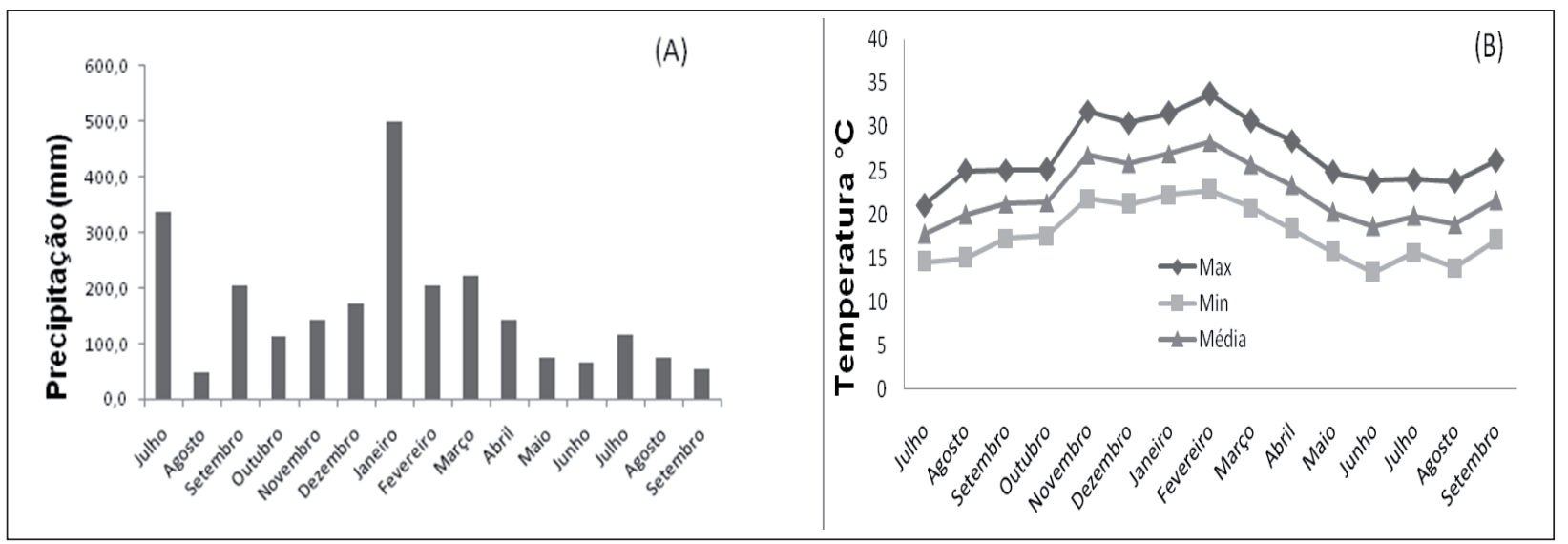

Fonte: Elaboração dos autores.

Figura 2. Variação da concentração $\left(\mathrm{g} \mathrm{kg}^{-1}\right)$ de: $(\mathrm{A})$ - Nitrogênio; (B) - Fósforo; (C) - Potássio; (D) - Cálcio; (E) Magnésio e (F) - Enxofre, e os teores máximo e mínimo indicados para o cultivo de bananeira (QUAGGIO; RAIJ; PIZA JÚNIOR, 1997) - agosto de 2009 - setembro de 2010. * Diferença significativa entre Cavendish e Prata segundo teste T Bonferroni a $5 \%$.

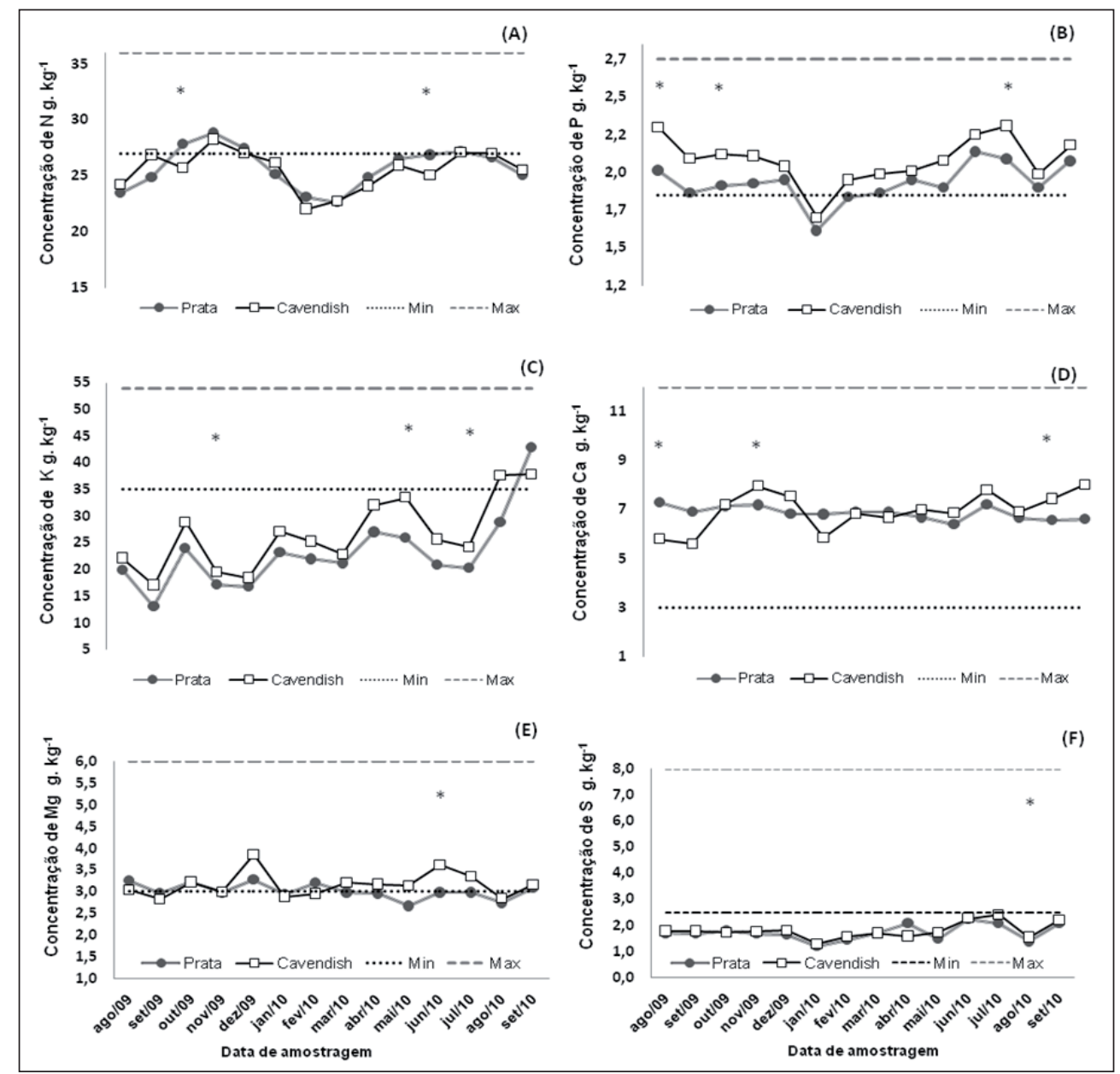

Fonte: Elaboração dos autores. 
A concentração de $\mathrm{P}$ na folha manteve-se dentro da faixa adequada (QUAGGIO; RAIJ; PIZA JÚNIOR, 1997) durante praticamente todo o período de avaliação, ocorrendo redução mais significativa na concentração em janeiro de 2010, elevando-se nos meses posteriores (Figura 2B). Em estudo de acúmulo de nutrientes pelas bananeiras cv. Prata e Grande Naine, Soares et al. (2008) observaram que o P foi o macronutriente menos absorvido (24,9 e 23,9 $\mathrm{kg} \mathrm{ha}^{-1}$, respectivamente), sendo exportado pelos frutos em pequenas quantidades $(3,2$ e $7,9 \mathrm{~kg}$ ha $^{-1}$ ) e, por isso, 72,2 e 63,3\% fora restituído ao solo. Além disso, Cavalcante et al. (2005) observaram ininterrupta translocação de fósforo entre plantas mãe e filha e vice-versa. Por estes motivos, acrescidos da tradicional adubação de produção realizada pelos bananicultores, no Vale do Ribeira, utilizando fertilizantes mistos contendo P (p. ex. 1407-28), independente do teor de P disponível no solo (MENDONÇA; PENTEADO; GODOY, 2006), mantendo os teores de $\mathrm{P}$ altos no solo (Tabela 2) pode-se explicar a concentração adequada de $\mathrm{P}$ nos bananais da região, durante todo o ano. Silva et al. (2002) citaram como adequada à concentração foliar de P de 1,5 a 1,9 $\mathrm{g} \mathrm{kg}^{-1}$, para bananeira cv PrataAnã, e tomando estes valores como referência para a cultivar citada haveria períodos com excesso de $\mathrm{P}$, principalmente, nos meses de menor temperatura (agosto de 2009 e junho e julho de 2010) (Figura 1B). A redução na concentração foliar de $\mathrm{P}$, ocorrida em janeiro de 2010, nas bananeiras dos dois subgrupos, pode ter sido ocasionada pelo excesso de chuva, reduzindo a disponibilidade de oxigênio do solo, prejudicando diretamente a absorção do P (STEPNIEWSKI; PRZYWARA, 1992), além das raízes que perdem a rigidez e apodrecem rapidamente pelo encharcamento do solo (SILVA; BORGES, 2008).

Foi observada a elevação da concentração foliar de K, do início (agosto de 2009) ao final do período (setembro de 2010), mantendo-se até julho de 2009 abaixo da faixa adequada para a cultura (QUAGGIO; RAIJ; PIZA JÚNIOR, 1997) (Figura 2C). Portanto, as doses de $\mathrm{K}$ utilizadas pelos produtores não foram suficientes para manter a concentração adequada, principalmente, devido o grande volume de chuvas (Figura 1A) e a tendência do K a ser lixiviado do solo (SANSOULET; CABIDOCHE; CATTAN, 2007) ou até mesmo da folha da bananeira (RÓBINSON; SAÚCO, 2010). Outro fator levantado por Teixeira, Zambrosi e Neto (2007) é que os valores padrões da concentração foliar de $\mathrm{K}$, apresentados na literatura nacional (QUAGGIO; RAIJ; PIZA JÚNIOR, 1997; MALAVOLTA; VITTI; OLIVEIRA, 1997), sejam superestimados para as condições climáticas dos bananais do Estado de São Paulo, visto que plantas de experimentos com adubação potássica adequada e altas produtividades não tem atingido esta concentração de K adequada. Silva et al. (2002) sugerem como concentração de $\mathrm{K}$ adequada na folha da bananeira Prata-Anã a faixa de 27 a $35 \mathrm{~g}$ $\mathrm{kg}^{-1}$. López et al. (2000) recomendam o valor crítico de $30 \mathrm{~g} \mathrm{~kg}^{-1}$ na folha de bananeira do subgrupo Cavendish, abaixo do qual se considera a planta deficiente em K.

Foram observados picos de aumento da concentração de $\mathrm{K}$ na folha das bananeiras de ambos os subgrupos nos meses de outubro de 2009, janeiro e abril de 2010 (Figura 2C), datas posteriores à adubação potássica parcelada, geralmente, nos meses de setembro, dezembro e fevereiro ou março (MENDONÇA; PENTEADO; GODOY, 2006).

Comparando as concentrações foliares de $\mathrm{K}$ nos meses de setembro de 2009 e 2010, verificase que as plantas se apresentam muito deficientes em K, em 2009 (20 e $22 \mathrm{~g} \mathrm{~kg}^{-1} \mathrm{~K}$, para o subgrupo Prata e Cavendish, respectivamente) e em 2010, apresentaram concentrações altas de K (43 e 37 $\mathrm{g} \mathrm{kg}^{-1} \mathrm{~K}$, para o subgrupo Prata e Cavendish, respectivamente) (Figura 2C). Esta variação pode ser explicada pela variação no regime pluviométrico devido o fenômeno "El Niño". Segundo Paula et al. (2010) a chuva tem sido alterada nas diferentes regiões do Brasil pelo "El Niño", fenômeno climático cuja fase positiva provoca chuvas freqüentes, acima do normal (ano de 2009), e 
a fase negativa, conhecida como "La Niña", a quantidade de chuva o ano é abaixo do normal (ano de 2010). Com base nestas observações fica clara a importância do monitoramento do estado nutricional, principalmente, em $\mathrm{K}$, por meio da análise química da folha da bananeira, e com base nos resultados programar a adubação potássica. Assim, no ano de 2009, a adubação potássica deveria ser realizada logo em agosto, com o aumento da temperatura e utilizando doses altas de $\mathrm{K}$, parcelada no período de adubação. Já em 2010, a adubação com K poderia ser realizada, depois de setembro, com doses mais baixas em relação a 2009. Estas considerações também podem ser feitas, em menor grau, para o $\mathrm{N}$.

As concentrações foliares de $\mathrm{Ca}$ ficaram dentro da faixa ideal (QUAGGIO; RAIJ; PIZA JÚNIOR, 1997, SILVA et al., 2002) para as bananeiras dos dois subgrupos (Figura 2D), em todo o período de avaliação. Godoy et al. (2009), em levantamento da fertilidade do solo de bananais da região do Vale do Ribeira, observaram que mais de $60 \%$ dos talhões amostrados apresentavam teores altos de $\mathrm{Ca}$ e $\mathrm{Mg}$, devido à aplicação periódica de calcário. Nas bananeiras do subgrupo Cavendish houve um pico da concentração foliar de Ca em novembro de 2009 (Figura 2D). Mahouachi (2009) observou aumento da concentração de $\mathrm{Ca}$ nas folhas de bananeira do subgrupo Cavendish (cv. Grande Naine) devido o estresse por seca, o que não ocorreu no presente experimento, na referida data. Segundo Diáz, Cayón e Mira (2007), problemas de deficiência de $\mathrm{Ca}$ em bananeiras ocorrem em condições de alta temperatura, luminosidade e umidade e baixa corrente de ar entre as folhas o que desfavorece a transpiração pelas plantas e, portanto, o fluxo de $\mathrm{Ca}$ na planta.

Houve oscilação da concentração foliar de $\mathrm{Mg}$ entre a condição adequada e deficiente, durante o período de avaliação, ficando em algumas datas no nível crítico (Figura 2E). A concentração de $\mathrm{Mg}$ na folha da bananeira pode ser reduzida pela concentração mais alta de K (FRANÇA et al., 2010) e vice-versa (MOSTAFA; SALEN; ABD EL-
MIGEED, 2007), pode ser aumentada com a maior quantidade de chuva acumulada entre as datas de coleta (SMITHSON, et al., 2004) ou por um período maior de seca (MAHOUACHI, 2009).

As concentrações foliares de S mantiveram-se abaixo da faixa ideal para a cultura, praticamente, durante todo o período de avaliação (Figura 2F). No caso do enxofre, tal fato pode ter ocorrido devido à utilização de fertilizante com alta concentração de NPK (p.ex. 14-07-28; 13-13-35) e baixo teor de S (MENDONÇA; PENTEADO; GODOY, 2006). Observou-se que no mês de janeiro de 2010 houve queda na concentração, onde o $\mathrm{S}$ pode ter sido mais lixiviado devido às altas precipitações no mês (aproximadamente $500 \mathrm{~mm}$ ). Foloni e Rosolem (2006) observam forte lixiviação de sulfato quando aplicado sulfato de amônio, independente da aplicação de calcário. Todavia, se considerarmos os valores adequados (1,7 a 2,0 $\left.\mathrm{g} \mathrm{kg}^{-1}\right)$ considerados por Silva et al (2002) as bananeiras do subgrupo Prata apresentaram concentração adequada durante o período de avaliação em 2009, ficando deficiente, apenas em janeiro e fevereiro de 2010, o que também pode ser justificado pelo excesso de chuvas com tendência de lixiviação do sulfato. Memon, Memon e Zia-Ul-Hassan (2005), em revisão sobre o uso da análise de planta como ferramenta para diagnóstico nutricional de bananeiras, citam que a deficiência de enxofre pode ser diagnosticada mais adequadamente se forem amostradas as folhas mais jovens, antes do florescimento.

A concentração de $\mathrm{Zn}$ nas folhas das bananeiras de ambos os subgrupos ficou abaixo da concentração adequada (Figura 3A) em várias datas de avaliação (dezembro de 2009, janeiro a março e de junho a julho de 2010). Rodrigues et al (2007) relatam que baixas concentrações foliares de $\mathrm{Zn}$ são comuns na região do Norte de Minas Gerais e associados às altas concentrações de $\mathrm{Zn}$ no solo, indicando restrição na disponibilidade desse nutriente para as plantas. Em relação à concentração de Zn nas folhas vários trabalhos vêm sendo realizados para definição do nível crítico mais adequado. Moreira 
e Fageria (2009) em trabalho de adubação com zinco encontraram a concentração foliar crítica deste nutriente de $12,9 \mathrm{mg} \mathrm{\textrm {kg } ^ { - 1 }}$, para bananeira do subgrupo Prata (Thap Maeo) semelhante ao recomendado por Silva et al. (2002) (14,0 $\mathrm{mg} \mathrm{kg}^{-}$ $\left.{ }^{1}\right)$ e Silva et al (2007) $\left(14,4 \mathrm{mg} \mathrm{kg}^{-1}\right)$, ambos para a bananeira Prata-Anã. Teixeira, Zambrosi e Neto (2007) encontraram a concentração foliar ótima de Zn de 17,3 \pm 0,6, derivado dos índices DRIS, para bananeira do subgrupo Cavendish. Considerando estes valores como padrão para as bananeiras do subgrupo Prata não houve deficiência de Zn em todo o período de avaliação.

A concentração foliar dos micronutrientes $\mathrm{Cu}, \mathrm{Mn}$ e $\mathrm{Fe}$ mantiveram-se dentro da faixa ideal (QUAGGIO; RAIJ; PIZA JÚNIOR, 1997), praticamente, durante todo o período de avaliação, nas bananeiras de ambos os subgrupos (Figura 3B, 3C e 3D). O cobre é um micronutriente extraído em pequenas quantidades pelas bananeiras (HOFFMANN et al., 2010b, MOREIRA; FAGERIA, 2009), sendo muito pouco utilizado nos programas de adubação devido ao fato que as deficiências deste nutriente em bananeiras são muito raras (ESPINOSA, 2006). Considerando as concentrações foliares adequadas sugeridas por Silva et al. (2002), na bananeira Prata-Anã (2,6 a $8,8 \mathrm{mg} \mathrm{kg}^{-1}$ ), as concentrações de $\mathrm{Cu}$ na folha deste cultivar foram até excessivas em algumas datas. No norte de Minas Gerais, Silva e Rodrigues (2001) observaram grande variação da concentração de $\mathrm{Cu}$ nas folhas da bananeira Prata-Anã e a deficiência deste em $43 \%$ dos bananais avaliados na região. $\mathrm{O} \mathrm{Fe}$, apesar de ser o segundo micronutriente mais extraído pela bananeira (HOFFMANN et al., 2010b) não é comum à observação de sintomas da sua deficiência na cultura da banana, sendo mais comum sua toxidez (ESPINOSA, 2006). As maiores concentrações de Fe nas folhas das bananeiras foram observadas logo após época de maior acúmulo de chuva (Figuras 1A e 3D), provavelmente devido a maior disponibilidade no solo ocasionado pelo excesso de chuva e condição de redução, como observado por Abreu, Fernandes e Ruivo (2007). Considerando as concentrações foliares adequadas de Fe recomendadas por Silva et al. (2002), nestas datas as concentrações foliares de Fe nas bananeiras do subgrupo Prata poderiam ser consideradas excessivas. O manganês é o micronutriente mais extraído pela cultura da banana (ESPINOSA, 2006), entretanto, em nenhuma data foi verificada a condição de deficiência segundo a concentração foliar deste (Figura 3C). Houve aumento da concentração foliar de Mn, em ambos os subgrupos, de setembro a novembro de 2009, coincidindo com o aumento da temperatura do ar (Figura 1B) e do fotoperíodo, contudo a concentração reduziu, em seguida, até janeiro de 2010. Segundo Mccain e Markley (1989) há acúmulo mais rápido de Mn em folhas expostas ao sol até o meio do verão, a partir de quando a concentração se tornou constante.

A concentração de boro nas folhas das bananeiras de ambos os subgrupos manteve-se adequada nos meses de setembro e outubro de 2009 e dezembro e janeiro de 2010 (Figura 3E). A partir de março de 2010, a concentração foliar de B ficou abaixo da adequada, em ambos os subgrupos, até setembro do mesmo ano. Segundo Mendonça, Penteado e Godoy (2006) é comum a observação de sintomas visuais da deficiência de B no Vale do Ribeira. Nóbrega et al. (2010) citam como sintomas característicos da carência de boro deformações nos limbos, que ficam estreitos com ondulações nos bordos, e às vezes somente a nervura central permanece, necrose nas margens das folhas sem clorose prévia, principalmente na ponta, a qual se encarquilha, clorose internerval e estrias perpendiculares às nervuras secundárias na face inferior e aparecimento de muitos filhotes com os sintomas ainda mais acentuados. Apesar de o boro ser susceptível a lixiviação (ROSOLEM; BÍSCARO, 2007) os meses de menor concentração coincidem com a época de menor acúmulo de chuva (Figura 1A), em relação aos períodos com concentração foliar adequada de B. Assim, parece que a menor quantidade de chuva é mais limitante para a disponibilidade de 
B no solo e/ou absorção de B pela bananeira, do que o excesso de chuvas. Por ser o B imóvel no floema de plantas que não produzem polióis (sorbitol, manitol e dulcitol) (SOUZA; OLIVEIRA; CASTIGLIONI, 2004), a concentração foliar pode ser reduzida em épocas de menor temperatura e menor disponibilidade de água. A mineralização da matéria orgânica, importante fonte de boro, também pode ser reduzida com a menor ocorrência de chuva e temperaturas mais baixas. Em setembro de 2009 houve aumento da concentração foliar de B, o que não ocorreu no mesmo mês do ano seguinte (Figura 3E), apesar das concentrações de B nas folhas, no mês de agosto de 2009 e 2010 de agosto, serem semelhantes, o volume de chuvas em setembro de 2010 foi muito menor (aproximadamente $50 \mathrm{~mm}$ ) em relação a setembro de 2009 (aproximadamente $200 \mathrm{~mm}$ ) (Figura 1A).

Figura 3. Variação da concentração (g.kg-1) de (A) - Zinco; (B) - Cobre; (C) - Manganês; (D)- Ferro; (E) - Boro e (F) - Sódio e os teores máximo e mínimo indicados para o cultivo de bananeira de acordo com (QUAGGIO; RAIJ; PIZA JÚNIOR, 1997) - agosto/2009 - setembro/2010. * Diferença significativa entre os subgrupos Prata e Cavendish segundo teste T Bonferroni a 5\%.

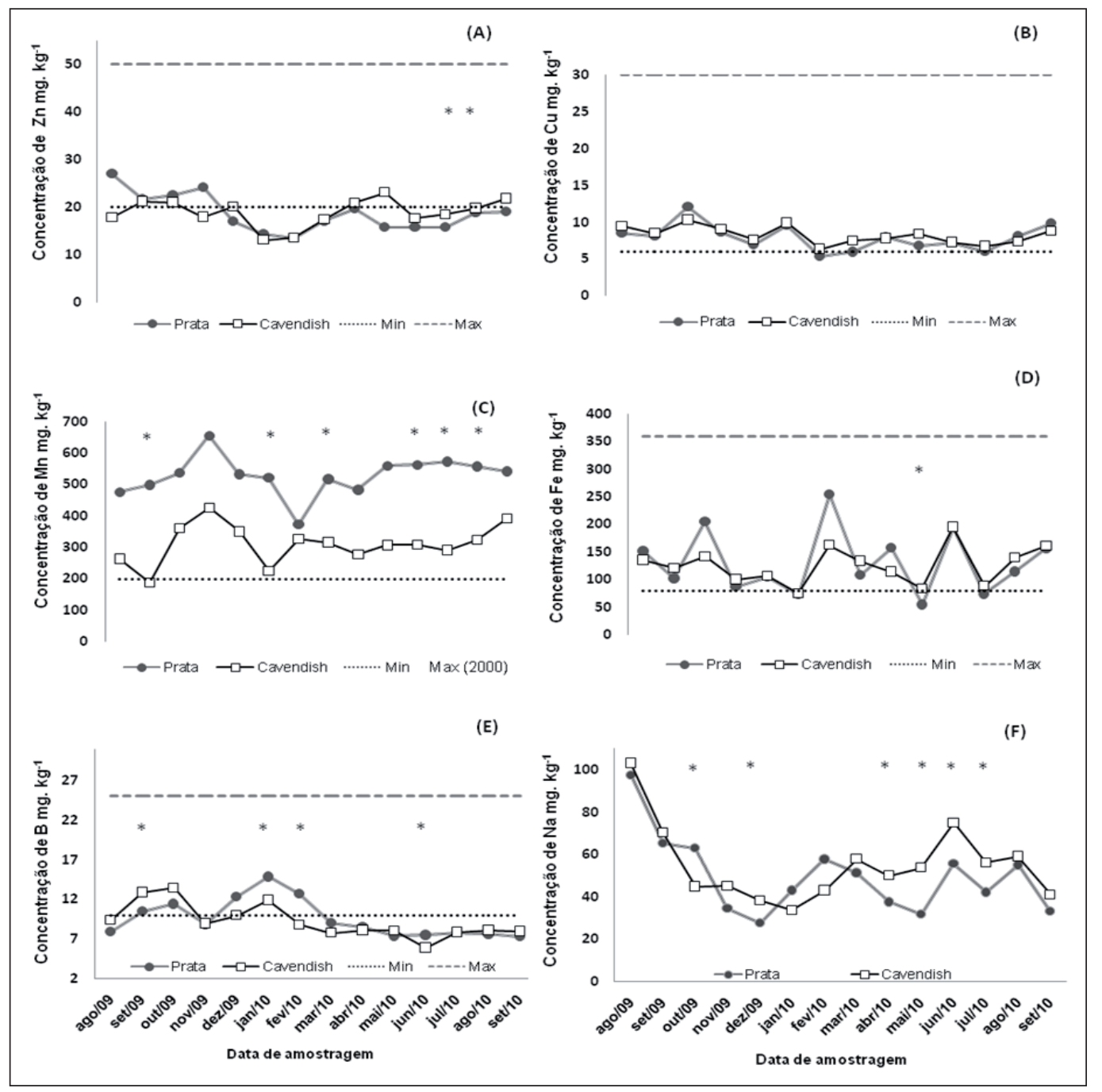

Fonte: Elaboração dos autores. 
Em relação à concentração foliar de sódio, houve redução acentuada nas folhas das bananeiras dos subgrupos Cavendish e Prata, de agosto a dezembro de 2009 (Figura 3F), época de maior volume de chuvas (Figura 1A). A partir de dezembro de 2009 houve aumento da concentração de $\mathrm{Na}$ nas folhas de ambos subgrupos, entretanto, este aumento é contínuo até junho de 2010, somente nas bananeiras do subgrupo Cavendish, enquanto nas bananeiras do subgrupo Prata há houve oscilação da concentração foliar de $\mathrm{Na}$ até setembro de 2010. Apesar da variação sazonal da concentração foliar de $\mathrm{Na}$, em nenhuma data foi atingido o nível tóxico citado por Moreira (1999) de $165 \mathrm{mg} \mathrm{kg}^{-1}$. Silva e Rodrigues (2001) encontraram concentrações foliares de $\mathrm{Na}$ de 10 até $1398 \mathrm{mg} \mathrm{kg}^{-1}$, no Norte de Minas Gerais, devido às condições edafoclimáticas e a água de irrigação utilizada. Apesar das maiores concentrações de sódio terem sido encontradas quando as concentrações foliares de $\mathrm{K}$ eram baixas (deficientes) não houve relação clara entre os dois elementos, como citado por Sathiamoorthy e Jeyabaskaran (2001). Segundo Shapira et al. (2009), devido à anatomia da folha da bananeira, o maior acúmulo de sódio ocorre nas margens das folhas, assim a parte da folha amostrada no presente experimento, e indicada para avaliação do estado nutricional, não deve ser a amais adequada para a detecção do excesso de $\mathrm{Na}$.

Houve algumas diferenças significativas na concentração dos nutrientes para as bananeiras do subgrupo Cavendish e Prata, durante período de avaliação. Dentre estas diferenças pode-se destacar maior concentração de $\mathrm{P}$ e $\mathrm{K}$, nas bananeiras do subgrupo Cavendish, em três datas de avaliação, e de Ca e Zn, em duas datas de avaliação. As bananeiras do subgrupo Prata apresentaram maior concentração, principalmente, de Mn (em seis datas de avaliação), B (em três datas de avaliação) e N (em duas datas de avaliação). As maiores concentrações de sódio foram observadas, principalmente, nas folhas das bananeiras do subgrupo Cavendish. Hoffmann et al. (2010a) observaram maior acúmulo total de N, P,
$\mathrm{K}, \mathrm{S}$ e Mg em bananeiras do subgrupo Prata (PrataAnã) em relação à do subgrupo Cavendish (Grande Naine). Em relação aos micronutrientes Hoffmann et al. (2010b) também observaram maiores quantidades absorvidas de Mn e B nas bananeiras do cultivar Prata-Anã em relação aos do subgrupo Cavendish (Grande Naine e Gros Michel). Soares et al. (2008), trabalhando com as cultivares Prata-Anã e Grande Naine (subgrupo Cavendish) concluíram que as cultivares têm exigências nutricionais e padrão de partição de nutrientes diferentes; assim, as plantas devem ser adubadas de forma diferenciada.

\section{Conclusões}

A maior variação entre os macronutrientes ocorreu para o $\mathrm{K}$ e o $\mathrm{S}$ e entre os micronutrientes, principalmente, para o Fe e o B.

As condições climáticas, principalmente a chuva, influenciaram as concentrações foliares de nutrientes, com destaque para o K, N, S, B e Fe.

As concentrações foliares de N, K, S, Zn e $\mathrm{B}$ indicaram condição marginal a deficiente na maior parte do período de avaliação, evidenciando potencial de resposta aa adubação.

Em algumas datas da avaliação, houve maior concentração foliar de $\mathrm{P}, \mathrm{K}, \mathrm{Ca}$ e Zn, nas bananeiras do subgrupo Cavendish, enquanto as bananeiras do subgrupo Prata apresentaram maior concentração foliar, principalmente, de Mn, B e N.

\section{Referências}

ABREU, E. M. A.; FERNANDES, A. R.; RUIVO, M. L. P. Variação temporal e vertical de atributos químicos de um gleissolo do rio Guamá cultivados com Canaranas. Revista Brasileira de Ciências do Solo, Viçosa, v. 31, n. 2, p. 277-285, 2007.

BORGES, A. L.; SOUZA, L. S. Nutrição e adubação na cultura da banana na região nordeste do Brasil. In: GODOY, L. J. G.; GOMES, J. M. (Ed.). Tópicos sobre nutrição e adubação da cultura da banana. Registro: UNESP, 2009. p. 1-31. 
BUSQUET, R. N. B. Análise de crescimento, fenologia $e$ acumulação de nutrientes de quatro genótipos de bananeira no Estado do Rio de Janeiro. 2006. Tese (Doutorado em Fitotecnia) - Universidade Federal Rural do Rio de Janeiro, Seropédica, RJ.

CAVAlCANTE, A. T.; SAMPAIO, E. V. S. B.; CAVALCANTE, U. M. T. Interdependência na absorção e redistribuição de fósforo entre planta mãe e filha de bananeira. Revista Brasileira de Fruticultura, Jaboticabal, v. 27, n. 2, p. 255-259, 2005.

CIIAGRO. Portal do Governo do Estado de São Paulo - centro integrado de informações agrometeorológica. 2010. Disponível em: <http://www.ciiagro.sp.gov.br>. Acesso em: 06 jul. 2010.

DIÁZ, A.; CAYÓN, G.; MIRA, J. J. Metabolismo del calcio y su relación con la "mancha de madurez" del fruto de banano. Una Revisión, Agronomía Colombiana, v. 25, n. 2, p. 280-287, 2007.

ESPINOSA, J. Nutrição e adubação da cultura da banana na América Central. In: GODOY, L. J. G. (Ed.). Anais do workshop sobre nutrição e adubação na cultura da banana. Pariquera-Açu: UNESP/POTAFOS, 2006. p. 6-57.

FOOD AGRICULTURE ORGANIZATION - FAO. Crops. 2010. Disponível em: <http://faostat.fao.org $>$. Acesso em: 01 dez. 2010.

FOLONI, J. S. S.; ROSOLEM, C. A. Efeito da calagem e sulfato de amônio no algodão transporte de cátions e ânions no solo. Revista Brasileira de Ciências do Solo, Viçosa, v. 30, n. 3, p. 425-432, 2006.

FRANÇA, F. G.; GODOY, L. J. G.; SANTANA, K. C. R.; FRANÇA, F. K.; FRANÇA, C. C. Estado nutricional e produtividade da bananeira cv. Grande Naine em função do parcelamento da adubação ou utilização de fertilizante de liberação controlada. In: CONGRESSO BRASILEIRO DE FRUTICULTURA, 21., 2010, Natal. Resumos... Natal: Sociedade Brasileira de Fruticultura, 2010. 1 CD-ROM.

FURTADO, E. L.; BUENO, C. J.; OLIVEIRA, A. L.; MENTEN, J. O. M.; MALAVOLTA, E. Relações entre ocorrência do Mal-do-Panamá em bananeira da cv. Nanicão e nutrientes no solo e nas folhas. Tropical Plant Pathology, Brasilia, v. 34, n. 4, p. 211-215, 2009.

GODOY, L. J. G.; MENDONÇA, J. C.; OLIVEIRA, C. A.; GOMES, J. M. Fertilidade do solo em bananais do vale do ribeira. In: GODOY, L. J. G.; GOMES, J. M. (Ed.). Tópico sobre nutrição e adubação da cultura da banana. Registro: UNESP, 2009, p. 121-143.

HARGER, N.; FIORETTO, R.; RALISCH, R. Avaliação nutricional da cultura da soja pelos métodos DRIS e níveis de suficiência. Semina: Ciências Agrárias, Londrina, v. 24, n. 2, p. 219-224, 2003.

HOFFMANN, R. B.; OLIVEIRA, F. H. T.; SOUZA, A. P.; GHEYI, H. R.; SOUZA JUNIOR, R. F. Acúmulo de matéria seca, e de macronutrientes em cultivares de banana irrigada. Revista Brasileira de Fruticultura, Jaboticabal, v. 32, n. 1, p. 268-275, 2010a.

HOFFMANN, R. B.; OLIVEIRA, F. H.; GHEYI, H. R.; SOUZA, A. P.; ARRUDAS, J. A. Acúmulo de matéria seca, absorção e exportação de micronutrientes em variedades de bananeira sob irrigação. Ciência e Agrotecnologia, Lavras, v. 34, n. 3, p. 536-544, 2010 b.

INSTITUTO DE ECONOMIA AGRÍCOLA - IEA. Área e produção de produtos da agropecuária. Disponível em: $<$ http://www.iea.sp.gov.br>. Acesso em: 05 abr. 2010.

LEONEL, S.; TECCHIO, M. A. Teores nutricionais em folhas e frutos de figueira, submetida a épocas de poda e irrigação. Semina: Ciências Agrárias, Londrina, v. 30, n. 2, p. 347-360, 2009.

LEPSCH, I. F.; PRADO, H.; MENK, J. R. F.; SAKAI, E.; RIZZO, L. T. B. Levantamento de reconhecimento com detalhes dos solos da região do Rio Ribeira de Iguape, SP. Instituto Agronômico, Secretaria de Agricultura do Governo do Estado de São Paulo. 1999. Mapa. Escala: $1: 250.000$.

LÓPEZ, A.; VARGAS, A.; ESPINOSA, J.; VARGAS, R. Sintomas de deficiencias nutricionales y otros desórdenes fisiológicos en el cultivo del banano (Musa AAA). San Jose: Intituto de La Potasa y el Fósforo, 2001. (Guia de Campo).

LOURES, S. S. P. Ambientes, uso e ocupação do solo e zoneamento estratégico para as sub-bacias dos rios Jacupiranga e Pariquera-Açu, Vale do Ribeira, SP. 2008. Tese (Doutorado em Engenharia Civil) - Universidade Federal de Viçosa, Viçosa, MG.

MAHOUACHI, J. Changes in nutrient concentrations and leaf gas exchange parameters in banana plantlets under gradual soil moisture depletion. Scientia Horticulturae, Amsterdam, v. 120, n. 4, p. 460-466, 2009.

MAlaVOlTA, E; VITTI. G. C; OliveirA, S. A. Avaliação do estado nutricional das plantas: princípios e aplicações. 2. ed. Piracicaba: POTAFÓS, 1997. p. 161232.

MCCAIN, D. C.; MARKLEY, J. L. More manganese accumulates in maple sun leaves than in shade leaves. Plant Physiology, Bethesda, v. 90, n. 4, p. 1417-1421, 1989.

MEMON, N.; MEMON, K. S.; ZIA-UL-HASSAN. Plant analysis as a diagnostics tool for evaluating nutricional 
requirements of bananas. International Journal of Agriculture \& Biology, Faisalabad, v. 7, n. 5, p. 824-831, 2005.

MENDONÇA, J. C.; PENTEADO, L. A. C.; GODOY, L. J. G. Nutrição e adubação da cultura da banana no Vale do Ribeira. In: GODOY, L. J. G. (Ed.). Anais do Workshop sobre nutrição e adubação na cultura da banana. Pariquera Açu: UNESP/POTAFOS, 2006. p. 5773.

MOREIRA, A.; FAGERIA, N. K. Yield, uptake, and retranslocation of nutrients in banana plants cultivated in upland soil of Central Amazonian. Journal of Plant Nutrition. Athens, v. 32, n. 3, p. 443-457, 2009.

MOREIRA, R. S. Banana: teoria e prática de cultivo. 2. ed. São Paulo: Fundação Cargill, 1999. 1 CD-ROM.

MOSTAFA, E. A. M.; SALEN, M. M. S.; ABD ELMIGEED, M. M. M. Response of plants to soil and foliar applications of magnesium. American-Eurasian Journal of Agricultural \& Environmental Science, Punjab, v. 2, n. 2, p. 141-146, 2007.

MUNOZ-CARPENA, A. R.; RITTER, A.; SOCORRO, A. R.; PÉREZ, N. Nitrogen evolution and fate in a Canary Islands (Spain) sprinkler fertigated banana plot. Agricultural Water Management, Columbus, v. 52, n. 2, p. 93-117, 2002.

NÓBREGA, J. P. R.; PEREIRA, W. E.; DIAS, T. J.; RAPOSO, R. W. C.; ARAÚJO, R. C.; OLIVEIRA, F. A. Poda do pseudocaule e doses de nitrogênio e boro na produção de mudas de bananeira 'Pacovan'. Semina: Ciências Agrárias, Londrina, v. 31, p. 1205-1208, 2010. Suplemento 1.

PAULA, G. M.; STRECK, N. A.; ZANON, A. J.; ELTZ, F. L. F.; HELWEIN, A. B.; FERRAZS. E. T. Influência do fenômeno el niño na erosividade das chuvas na região de Santa Maria (RS). Revista Brasileira de Ciência do Solo, Viçosa, v. 34, n. 4, p. 1007-1479, 2010.

QUAGGIO, J. A.; RAIJ, B. van; PIZA JÚNIOR, C. T. Recomendações de adubação e calagem para o Estado de São Paulo. 2. ed. Campinas: Instituto Agronômico/ Fundação IAC, 1997. 285 p. (Boletim técnico, 100).

RÓBINSON, J. C.; SAÚCO, V. G. Bananas and plantains. $2^{\text {nd }}$ ed. London: CAB International, 2010. 311 p. (Crop production science in horticulture series, 19).

RODRIGUES, M. G. V.; RUGGIERO, C.; NATALE, W.; PACHECO, D. D. Nutrição e produção da bananeira 'Prata-anã' adubada com zinco e boro diretamente no rizoma, via muda desbastada. Revista Brasileira de Fruticultura, Jaboticabal, v. 29, n. 3, p. 645-651, 2007.
ROSOLEM, C. A.; BÍSCARO, T. Adsorção e lixiviação de boro em Latossolo vermelho-amarelo. Pesquisa Agropecuária Brasileira. Brasília, v. 42, n. 10, p. 14731478, 2007.

SAKAI, E.; LEPSCH, I.F;AMARAL,A.Z. Carta de Solos

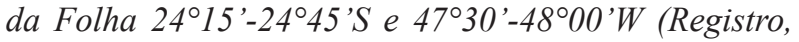
Juquiá, Pariqüera-Açu e Iguape). Levantamento pedológico de reconhecimento - semidetalhado da Região do Rio Ribeira de Iguape no Estado de São Paulo. Secretaria de Agricultura e Abastecimento do Estado de São Paulo; Instituto Agronômico de Campinas. 1983. Escala 1:100.000.

SANSOULET, J.; CABIDOCHE, Y. M.; CATTAN, $\mathrm{P}$. Adsorption and transport of nitrate and potassium in Andosol under banana (Guadaloupe, French West Indies). European Journal of Soil Science, Madison, v. 58, n. 2, p. 478- 489, 2007.

SATHIAMOORTHY, S.; JEYABASKARAN, K. J. Potassium management of banana. IPI/NARCTT Regional Workshop: Potassium and Water Management in West Asia and North Africa, Amman (JOR), 2001.

SHAPIRA, O.; KHADKA, S.; ISRAELI, Y.; SHANI, U.; SCHWARTZ, A. Functional anatomy controls ion distribution in banana leaves: significance of $\mathrm{Na}^{+}$ seclusion at the leaf margins. Plant Cell Environ, Oxford, v. 32, n. 5, p. 476-85, 2009.

SILVA, E. B.; PINHO, P. J.; CARVALHO, J. G.; RODRIGUES, M. G. V. Nível de suficiência de zinco para bananeira 'Prata Anã' por meio do DRIS. Acta Scientiarum. Agronomy, Maringá, v. 29, n. 1, p. 69-74, 2007.

SILVA, E. B.; RODRIGUES, M. G. V. Levantamento nutricional dos bananais da região norte de Minas Gerais pela análise foliar. Revista Brasileira de Fruticultura, Jaboticabal, v. 23, n. 3, p. 695-698, 2001.

SILVA, J. T. A. S.; BORGES, A. L. Solo, nutrição mineral, e adubação da bananeira. Informe Agropecuário, Belo Horizonte, v. 29, n. 245, p. 25-37, 2008.

SILVA, J. T. A.; CARVALHO, J. G. Avaliação nutricional de bananeira Prata-Anã (AAB), sob irrigação no semiárido do Norte de Minas Gerais, pelo método DRIS. Ciência e Agrotecnologia, Lavras, v. 29, n. 4, p. 731-739, 2005.

SILVA, J. T. A. da; BORGES, A. L.; DIAS, M. S. C.; COSTA, E. L.; PRUDÊNCIO, J. M. Diagnóstico nutricional da bananeira 'Prata' Anã' para o norte de Minas Gerais. Belo Horizonte: EPAMIG, 2002. 16 p. (EPAMIG. Boletim técnico, 70). 
SMITHSON, P. C.; MCINTYRE, B. D.; GOLD, C. S.; SSALI, H.; NIGHT, G.; OKECH, S. Potassium and magnesium fertilizers on banana in Uganda: yields, weevil damage, foliar nutrient status and DRIS analysis. Nutrient Cycling in Agroecosystems, London, v. 69, n. 1, p. 43-49, 2004.

SOARES, F. A. L.; GHEYI, H. R.; OLIVEIRA, F. H. T.; FERNANDES, P. D.; FRANCISCCO, A. N. A.; SILVA, F. V. Acúmulo, exportação e restituição de nutrientes pelas bananeiras "Prata Anã" e "Grand Naine, Ciência Rural, Santa Maria, v. 38, n. 7, p. 2054-2058, 2008.

SOUZA, A.; OLIVEIRA, M. F.; CASTIGLIONI, V. B. R. O boro na cultura do girassol. Semina: Ciencias Agrárias, Londrina, v. 25, n. 1, p. 27-34, 2004.

STEPNIEWSKI, W.; PRZYWARA, G. The influence of soil oxygen availability on yield and nutrient uptake $(\mathrm{N}$, $\mathrm{P}, \mathrm{K}, \mathrm{Ca}, \mathrm{Mg}, \mathrm{Na}$ ) by winter rye (Secale cereale). Plant and Soil, Crawley, v. 143, n. 2, p. 267-274, 1992.
TEIXEIRA, L. A. J.; ZAMBROSI, F. C. B.; NETO, J. E. B. Avaliação do estado nutricional de bananeiras do subgrupo Cavendish no estado de São Paulo: Normas DRIS, e níveis críticos de nutrientes. Revista Brasileira de Fruticultura, Jaboticabal, v. 29, n. 3, p. 613-620, 2007.

TURNER, D. W.; LAHAV, E. Temperature influences nutrient absorption and uptake rates of bananas grown in controlled environments. Scientia Horticulturae, Amsterdam, v. 26, n. 4, p. 311-322, 1985.

WERLE, R.; GARCIA, R. A.; ROSOLEM, C. A. Lixiviação de potássio em função da textura e da disponibilidade do nutriente no solo. Revista Brasileira de Ciências do Solo, Viçosa, v. 32, n. 6, p. 2297-2305, 2008. 